\title{
El Shahnamé de Ferdousí: la historia de Siyawush, desde su nacimiento hasta la prueba de fuego
}

\section{Ferdowsi's Shahnameh: The Story of Siavush, from His Birth to His Passage through Fire}

\author{
Abol Qasem Ferdousí \\ Traducción, introducción y notas | Translation, \\ Introduction and Notes \\ Shekoufeh Mohammadi Shirmahaleh ${ }^{1}$ \\ Instituto de Investigaciones Filológicas \\ Universidad Nacional Autónoma de México \\ shekufe@hotmail.es
}

Resumen: El Shahnamé de Ferdousí es la épica nacional de Irán. La historia del príncipe Siyawsuh es uno de los pasajes más largos del libro y pertenece al ciclo heroico de la obra. La vida de Siyawush se puede dividir en tres momentos. Aquí ofrecemos una traducción al castellano del primer momento que narra su vida desde su nacimiento hasta su paso por el fuego.

Palabras clave: Shahnamé, Ferdousí, Siyawush, Kawús, Sudavé

Abstract: $\quad$ Ferdowsi's Shahnameh is the national epic of Iran. The story of prince Siavush is one of the largest passages of the book and belongs to the heroic cycle of the work. The life of Siavush can be divided in three moments. Here we offer a translation into Spanish of the first moment that narrates his life from his birth to his passing through fire.

Keywords: Shahnameh, Ferdowsi, Siavush, Kavous, Soudabeh

Recibido: $\quad 3$ de mayo de 2019

Aceptado: $\quad$ 10 de junio de 2019

1 Esta traducción se realizó gracias al apoyo del proyecto PAPIIT IA 400518 "El recorrido literario del mito de Siyawash desde el Shahnamé de Ferdousí hasta el Sendebar medieval". 


\section{Introducción}

La historia de Siyawush es una de las más extensas en la épica nacional de Irán, el Shahnamé, obra del poeta persa Abol Qasem Ferdousí (siglos X- XI). El Shahnamé suele estudiarse como una obra dividida en tres ciclos: el mítico, el heroico y el histórico. El pasaje que narra la vida, el exilio y la muerte del príncipe Siyawush pertenece al ciclo heroico y se entreteje con la vida de Rostam, el mayor héroe del Shahnamé.

La vida de Siyawush se puede dividir en tres momentos cruciales: el primero abarca desde su nacimiento hasta su sometimiento a la prueba de fuego; el segundo involucra su exilio al mítico Turán y su asesinato; el tercero comprende el nacimiento de su hijo Kay Josrow y la venganza de su sangre, que entendemos como su resurrección. Como muchas otras de las historias del Shahnamé, la de Siyawush se nutre de un rico fundamento mítico; además, está estrechamente vinculada con prácticas rituales que han sobrevivido hasta nuestros días.

A lo largo de los siglos y desde al menos el siglo v a. C., Siyawush ha estado presente en la mitología de Irán y Asia central con diferentes dimensiones: como deidad de la vegetación en el marco de un mito agrícola, como caballo totémico, como deidad solar, y finalmente como príncipe (Hosurí 2004: 4049). El Shahnamé de Ferdousí es el único documento escrito que se conserva hasta la actualidad que da cuenta de la historia de Siyawush. En una primera lectura parece que Ferdousí narra su historia con base en la etapa más tardía de su existencia, es decir como príncipe. Sin embargo, como ocurre casi con todas las historias de los primeros dos ciclos de la obra, la narración poética encierra y revela en todo momento las diferentes dimensiones mitológicas, hecho que una lectura más cuidadosa deja en claro. Por ejemplo, la dimensión totémica está presente tanto en el nombre del personaje (Siyawush significa 'caballo negro'), como en su relación existencial con su caballo negro, Shabrang. Su dimensión divina como deidad solar se deja entrever en metáforas y descripciones solares que hemos señalado en la traducción. Pero su aspecto mitológico más evidente en el Shahnamé es el que tiene que ver con su función como deidad de vegetación.

Según un antiguo mito agrícola Siyawush es el hijo de la Gran Diosa Ma$\mathrm{dre}^{2}$ y se vuelve víctima de su ira porque rechaza el alocado amor que ella le

2 Esta diosa no es la misma que la diosa madre de la tierra, sino que se parece más a diosas mayores como la Pínikir elamita, perteneciente al neolítico matriarcal (cuarto milenio a. C.) [Bahar 2014: 393-394]. 
declara y no se deja seducir. La diosa que, como es bien sabido, es a la vez doncella, ninfa y bruja (que da vida, mata y transforma la muerte de nuevo en vida); 3 mata a su hijo después de haberlo parido para después hacerlo regresar al mundo de los vivos. Esta cíclica muerte y resurrección que en cada una de sus fases dura lo que durarían el invierno-otoño y el verano-primavera respectivamente, fija a Siyawush como la deidad de la vegetación: pues cuando está en el mundo de los vivos todo está verde y cuando baja al inframundo, todo se seca.

Ahora bien, el Shahnamé de Ferdousí conserva estas funciones míticas de Siyawush de dos maneras: por un lado, mediante un estilo narrativo que va de su nacimiento al exilio y muerte, para culminar con la resurrección de su esencia en forma de un hijo que lo venga y una detallada narración de los hechos que no deja fuera a la diosa y la relación que Siyawush tiene con la vida vegetal argumentando que cuando se va de Irán a Turán ${ }^{4}$ hay una gran sequía en su país de origen, o que cuando muere y su sangre cae sobre la tierra nace de ella una planta que lleva su rostro trazado en sus hojas. Por otro lado, esta fidelidad mitológica se consigue gracias al uso de descripciones y metáforas vegetales cada vez que se habla de Siyawush, algunas de las cuales se observan en esta traducción.

En cuanto a la presencia de la diosa en esta historia, cabe mencionar que el pasaje nos presenta una mujer única en todo el Shahnamé, la madrastra de Siyawush: Sudavé. Antes del nacimiento de Siyawush, Ferdousí nos presenta a una Sudavé bella, sabia y valiente de quien se enamora perdidamente el rey iraní Kawús. Después, la misma mujer vuelve a aparecer cuando Siyawush es un adolescente, esta vez como esposa de Kawús y madrastra de Siyawush, con características muy diferentes a su primera aparición: pues en esta segunda etapa es una mujer malvada y engañosa que termina causando la muerte del joven príncipe. De este modo, dos de las fases de la Gran Diosa se ven reflejadas en Sudavé: la doncella y la ninfa. La tercera fase se divide en tres mujeres: la hechicera, que ayuda a Sudavé; su primera esposa, hija de Pirán, cuyo nombre no conocemos; y Faranguís, su segunda esposa. ${ }^{5}$

3 Véase, por ejemplo, Marija Gimbutas 2001: 316.

4 En la visión mitológica mazdea, lo iranio está relacionado con vida y lo foráneo o no propio con la muerte. De ahí que el exilio de Siyawush signifique su viaje del mundo de los vivos al inframundo.

5 Estos personajes pertenecen al segundo y al tercer momento de la vida de Siyawush, por lo tanto los trataremos con más detalle en las próximas traducciones. 
El pasaje cuenta además el enamoramiento de la diosa de su hijo cuando narra los intentos de seducción que Sudavé realiza con Siyawush. Igual que en el mito, en la historia del Shahnamé, Sudavé es la causante del destierro y muerte de Siyawush y cumple esta función a través del engaño: acusa a Siyawush de haber querido forzarla, le impone una peligrosa prueba de fuego que podría costarle la vida y, finalmente, hace que su padre Kawús sienta rencor por él, hecho que provoca su exilio a Turán-inframundo y su injusto asesinato a manos del hermano del rey de Turán. Son justamente estas características las que hacen única a Sudavé, pues ninguna otra mujer del Shahnamé es maléfica ni engañosa.

Así pues, la historia de Siyawush en el Shahnamé de Ferdousí alberga, además de lo legendario, lo mítico y lo totémico, esto sin hablar de lo ritual que aparece más bien en el segundo momento de su vida. Esta riqueza cuentística, recogida en el siglo vi en el Jodaynamag sasánida y poco después en la historia coránica de Yusuf y Zulaija, resultó ser una fuente de inspiración también para textos literarios posteriores al Shahnamé, como el Sindbadnamé en prosa, de Zahirí Samarqandí; el Sindbadnamé en verso, de Azod Yazdí, y posteriormente, el Sendebar de la España medieval.

Antes de pasar a la traducción, hacemos una breve presentación de los personajes que aparecen en este fragmento. Cabe mencionar que el Shahnamé de Ferdousí tiene sus propias divisiones internas para cada historia. Los títulos que aparecen son los de estas secciones, puestas por el poeta mismo. Para la traducción nos hemos basado en la edición de Yalal Jaleqi Motlaq del Shahnamé de Ferdousí y para todos los nombres y palabras del persa hemos optado por una transcripción sencilla, y no por una transliteración, con el fin de facilitar la lectura.

\section{Breve presentación de los personajes}

KAwús: rey de Irán. De la descendencia de Iray, hijo de Fereydún.

SudAvÉ: esposa de Kawús. Hija del rey de Hamawarán.

SiYAwUSH: hijo de Kawús.

Rostam: héroe de Zabolestán. Hijo de Zal, rey de Zabolestán. Maestro y cuidador de Siyawush.

GIV, GUDARZ y Tus: héroes de la corte de Irán.

GARSIVAZ: hermano de Afrasyab, rey de Turán.

Herzbad: siervo de Kawús y el amo de llaves de su serrallo. 


\section{La historia de Siyawush en el Shahnamé de Ferdousí Momento primero}

\section{La historia de Siyawajsh}

¡Oh elocuente de mente despierta! Compón una bella historia ahora. Cuando la palabra iguala la sabiduría, el alma del poeta está en paz. Quien alberga malos pensamientos y a pesar de esta maldad, presume de bondad, será señalado y descubierto por los sabios. Pero nadie ve sus propios defectos; uno siempre piensa que es luminoso su proceder. Para que se haga justicia, cuando compones tu palabra, muéstrala a los sabios. Si a ellos les gusta, será aceptada y el agua correrá en tu río, ${ }^{6}$ como corren las lágrimas en los ojos.

Vuelve ahora a las palabras del sabio, mira a ver qué dice el hombre poeta. Estas historias han envejecido de raíz, pero el tiempo antiguo se renovará. Si la vida es prolongada, si permanezco largamente en esta bella doctrina, quedará de mí un árbol frutal; su fruta lloverá sobre el pasto sin cesar. Han pasado por él 58 años y muchas cosas sorprendentes le han sucedido, pero la ambición no mengua con los años: pide más días al calendario y a la fortuna. ¿Qué dijo de esto el sacerdote primero? Que “lo viejo nunca se vuelve nuevo". Mientras dures, sé elocuente, sé sabio y de buen talante. Cuando te vayas, el Creador decidirá si tu lugar bueno o malo será. Mira a ver qué siembras; cosecharás lo mismo. De las palabras que digas, oirás lo mismo. Quien habla suavemente, no escuchará de nadie palabras ásperas. ¡En el mundo no busques excepto la bondad!

\section{El comienzo de la historia}

Así contó el sacerdote que un día, al levantarse el clamor del gallo, Tus, Giv hijo de Gudarz, y algunos jinetes más, partieron alegremente del palacio del rey, y como halcones y leopardos en busca de presa fueron al llano de Daquy para cazar onagros. Atraparon y tiraron a muchos, juntaron lo que les serviría de comida por 40 días. El país de los turcos estaba cerca de este lugar, su suelo estaba oscuro por la presencia de tantas tiendas. ${ }^{7}$ De lejos divisaron

6 Serás reconocido.

7 Se refiere a las tiendas de campaña de los turcos nómadas. Repleto de estas referencias, el pasaje muestra el contraste entre una civilización sedentaria, la iraní, y una nómada, la turaní. 
un matorral, cerca de la frontera de los jinetes de Tur. ${ }^{8}$ Giv y Tus cabalgaron por delante y les siguieron otros jóvenes valientes. En el matorral, encontraron a una bella mujer. Ambos, con los labios llenos de sonrisa, se apresuraron hacia ella. Como su rostro no había en el mundo y de belleza nada le faltaba. Tus le preguntó: “¡Oh luna hechicera! ¿Quién te dirigió a este matorral?” Así respondió que "Anoche, mi padre me pegó y abandoné mi hogar y mi país: en la noche oscura vino ebrio de una fiesta y, al verme de lejos, furioso sacó una daga de acero y quiso separarme del cuerpo la cabeza". El héroe le preguntó por su linaje, y ella nombró a varios cipreses;9 le dijo: "Soy pariente de Garsivaz, mi linaje asciende al rey Fereydún”. Le preguntó: “Cómo llegaste a pie hasta aquí? Pues viniste sin caballo y sin guía”. Así respondió: "Mi caballo se quedó en el camino, se cansó y me dejó tirada en el suelo; yo poseía infinito oro y joyas, llevaba una corona dorada en la cabeza; me los quitaron en aquella colina, me golpearon con la funda de una espada. Cuando mi padre cobre conciencia, sin duda enviará a veloces jinetes en pos de mí; vendrá mi madre, la tazí, ${ }^{10}$ no querrá que deje atrás este lugar". El calor de su cariño entró en el corazón de los héroes; de la cabeza de Tus, hijo de Nowzar, escapó la vergüenza y reclamó: "Fui yo quien encontró a esta turca, " yo, que cabalgaba veloz al frente de todos". Giv le contestó: “¡Oh, comandante del ejército real! ¿No estaba yo contigo cabalgando a la par al frente de los demás jinetes?” Pero Tus, hijo de Nowzar, le debatió y dijo: "Mi caballo llegó ahí antes". Giv le respondió: “No digas eso. Era yo quien, en cacería, galopaba al frente. Un hombre verdadero no debe disputar a quien le habla apropiadamente". Sus palabras alcanzaron tal agresión que dijeron: "Hay que cortarle la cabeza a esta luna". ${ }^{12}$ Como se alargó la disputa,

8 La tierra mítica de Turán, tierra de turcos, toma su nombre de Tur, hijo de Fereydún, quien fue su primer rey.

9 El ciprés es una metáfora muy común para describir reyes, príncipes y princesas y además de referirse a la altura de estatura y lo esbelto de la figura, alude mitológicamente a la función de las deidades de fertilidad que en el marco de la ética mazdea se concibieron además como deidades de la luz y la bondad.

1o Tayiko. Estos alegatos dejan en claro que la mujer no es irania, sino turaní. Este hecho tiene implicaciones interesantes en la mitología persa en tanto que advierte sobre posibles peligros derivados de lo ajeno.

"Aquí, Ferdousí juega con la palabra tork que al tiempo que significa 'turco/a' designa ciertas características físicas; es especialmente en lo que a la forma de los ojos y las cejas se refiere. Es muy común en la poesía clásica persa leer descripciones como "ojos turcos", que señala una belleza indómita y sangrienta.

12 También una metáfora muy común para describir la belleza tanto de hombres como mujeres. Igual que el ciprés, la luna es símbolo de fertilidad y solo los personajes con carga positiva son equiparados con ella. 
uno de los héroes se interpuso y dijo: "Lleven este asunto ante el rey de Irán y obedezcan lo que él decrete”. Los dos aceptaron su juicio y se encaminaron hacia el rey de Irán.

Al ver el rostro de la doncella, Kawús sonrió y se mordió el labio. Les dijo a los dos guerreros: "Se acabó lo que sufristeis por el camino. Pasemos el día hablando de cómo los [hombres] valientes como leopardos saben cazar el sol mismo. Sea venado o gacela robacorazones, una caza así solo es merecida al soberano”. El rey le preguntó: “¿A quién asciende tu linaje, tú que eres bella como una parí?"13 Ella respondió: "De parte de mi madre, soy de la progenie de la reina de los turcos, y el linaje de mi padre asciende a Fereydún. El comandante Garsivaz es mi abuelo. Tras la frontera, su tienda es el centro del reino". Kawús le dijo: "Sería una lástima que este rostro, esta cabellera y este linaje se los llevara el viento. ¿Quisieras quedarte en mis dorados aposentos y ser la cabeza de mis caras de luna?"14 Ella respondió: "Entre todos los valientes que he visto, te elijo a ti".

El rey mandó al ídolo a su harem y ordenó que se sentara en el trono. La engalanaron con seda amarilla, con rubíes, turquesas y lapislázuli. Por lo demás, por gracia del Creador, era todo lo que tenía que ser: como un rojo rubí jamás tallado. ${ }^{5}$

\section{Palabra acerca del nacimiento de Siyawajsh}

De este mundo no había pasado mucho cuando el color de aquella espléndida primavera cambió. Le dijeron al rey Kawús: "La luna afortunada te ha bendecido: ha sido creado un niño venturoso, ahora ¡hay que subir el trono hasta las nubes! $!^{16}$ Ha nacido de ella, como una parí, un niño cuyo rostro se parece a los ídolos de Azar". ${ }^{17}$ Todo el mundo hablaba de aquel pequeño, porque nadie ha-

13 Hada. Con el uso de esta palabra, Ferdousí confirma la naturaleza no humana de la mujer hallada, hecho que la descripción del marco espaciotemporal en que la encuentran ya había anticipado, pues los paisajes de caza con abundante vegetación y agua son lugares comunes de aparición de hadas en los cuentos persas. Además, el hecho de que esta mujer no tenga un nombre es otro indicio de lo mismo.

14 ¿Quieres ser mi preferida entre las mujeres del harem?

15 Hace referencia a la virginidad de la mujer.

16 Este verso está repleto de elementos de fertilidad que al estar relacionados con la bondad auguran que el recién nacido será un ser luminoso y virtuoso.

17 Según Yalal Jaleqi Motlaq, este verso hace referencia a Azar, padre de Abraham, que tenía mucha fama en la talla de ídolos (Ferdousí 2014, vol. 9: 567). 
bía visto jamás tal rostro y tal cabellera. El rey le dio como nombre Siyawajsh ${ }^{18}$ y dividió por él la rueda giratoria. ${ }^{19}$ Como él conocía las cuentas del alto cielo, y sabía leer en él lo bueno, lo malo, el cómo y el cuánto, vio que era nefasta la estrella de aquel niño y al ver dormida su fortuna, se entristeció. Vio que sufriría a manos de buenos y malos, y lo encomendó al Creador. ${ }^{20}$ Así pasaba el mundo hasta que un día Tahamtán ${ }^{21}$ vino ante el rey y le dijo: "Debo ser yo quien críe a este niño de pecho, ya que tus nanas no tienen la madera, no hay en el mundo mejor nodriza que yo". El rey reflexionó largo rato y vio que esta idea no pesaba sobre su corazón. Al niño que era sus ojos y su corazón, se lo dio a Rostam, el afable héroe buscador del mundo. Tahamtán se lo llevó a Zabolestán y le hizo un sitio en el jardín de flores. Le enseñó el qué, el cómo y el cuánto de la equitación, del uso de la flecha, el arco, la soga, las riendas y la montura, del comportamiento en las fiestas, del beber vino, de los halcones y los leopardos de caza, de la justicia y la injusticia, de la corona y el trono, de la conversación, de la guerra y la dirección de la tropa. Le enseñó todas las artes y mucho sufrió hasta que el árbol dio frutos. Siyawush se convirtió en un héroe tal que nadie en el mundo lo superaba.

Cuando pasó un tiempo y él se hizo más alto, fue con una soga hacia el cuello del león: le dijo al venturoso Rostam: "Necesito ver al rey. Tanto has sufrido y el cuerpo has desgastado para enseñarme las artes de los reyes. Ahora mi padre debe ver las artes que me ha enseñado el héroe de cuerpo de elefante". El héroe de corazón de león preparó el viaje: hizo cabalgar a sus enviados a

18 El nombre de este personaje se ha registrado como Siyawajsh y Siyawush según las necesidades métricas y rítmicas del poema.

19 Midió su fortuna con el astrolabio (Ferdousí 2014, vol. 9: 569). Sin embargo si tomamos en cuenta el significado literal del verso, otra interpretación es posible: Kawús es el rey del mundo y según las fuentes mazdeístas es un personaje cuya majestuosidad casi iguala la de Yamshid. Ahora bien, si consideramos que a Siyawush se le atribuyen las características de una deidad solar (Hosurí 2004: 47-49), podemos interpretar que al nacer Siyawush, que es el sol, Kawús le asigna un lugar en el cielo dividido en fracciones que marcarán las diferentes fases del viaje del sol en el firmamento. Con este verso, Ferdousí conserva con sabiduría los atributos míticos del personaje.

20 El hecho de que la madre del niño sea de una tierra no irania contribuye a que en su destino se mezclen lo bueno y lo malo; esta lectura de las estrellas confirma lo que las descripciones de la madre de Siyawush habían anticipado en los primeros versos del pasaje.

${ }^{21}$ Tahamtán, que significa 'robusto' y 'poderoso', es el apodo de Rostam, el héroe de más renombre que todos en el Shahnamé. Hijo de Zal y Rudabé, viene al mundo por un acontecimiento mágico dirigido por el ave Simorg. Las hazañas de Rostam son cuentos épicos y míticos originarios del sudeste de Irán, Pakistán y Afganistán, y muy populares en gran parte de Asia central. 
todas partes para que trajeran caballos, siervos, plata y oro, el sello, el trono, el sombrero ${ }^{22}$ y el cinturón. ${ }^{23}$ De lo que se debe vestir, de lo que se debe tender, trajo de todas partes lo que se debe traer. Si de todas estas cosas algo faltaba en el tesoro de Rostam, mandó que rápido lo trajeran de otros lados del mundo. Así lo encaminó y la tropa puso sus ojos sobre Siyawush. Tahamtán lo acompañó para que el guerrero no estuviera triste. Como deseaban contentar al renombrado, ornamentaron el mundo como es debido: mezclaron el oro y el ámbar y desde la cúpula lo arrojaron sobre su cabeza. El mundo se llenó de alegría y riquezas y las puertas, los techos y las calles, estaban todos adornados; bajo los cascos de los caballos tazíes, sonaban las monedas, y en todo Irán no se veía ni una sola persona que estuviera triste; de un extremo a otro, las crines de los caballos estaban untadas de almizcle, vino y azafrán.

Cuando Kawús se enteró de la llegada del bienaventurado Siyawajsh, ordenó que Giv y Tus, al frente de la tropa, fueran a recibirlo con alegría, elefantes y tambores. Se reunieron todos los renombrados: por un lado, Tus, y, por el otro, Rostam de cuerpo de elefante. Deslizándose, fueron ante el rey; pues iban acompañando a un joven árbol repleto de frutos. ${ }^{24}$ Cuando se acercó al palacio del rey Kawús, se levantó bullicio y le abrieron camino. En cada esquina, 300 siervos, con incensarios que desprendían agradables aromas, esperaban con los brazos cruzados, ${ }^{25}$ mirando a Siyawajsh de espíritu libre, entre ellos. Le arrojaron mucho oro y joyas y lo alabaron.

Cuando vio a Kawús en el trono de marfil, portando en su cabeza una corona de brillantes rubíes, primero lo alabó y se prosternó ante él: contando sus

22 Debido a la forma de las coronas de la época sasánida, la palabra sombrero kolah se utiliza en el Shahnamé como alternativa a tay, 'corona'.

23 Además de ser parte del atuendo real, hace referencia a kostí, una especie de fino cinturón de lana que los fieles del mazdeísmo llevan puesto en vigilia, desde los 15 años. "Ceñirse el cinturón" es una expresión muy común en la lengua persa, que significa prepararse para hacer algo importante, como cuando al despertar, el devoto mazdeo se ciñe el kostí y se dispone a comenzar otro día asistiendo a Mazda y combatiendo contra Ahrimán: pues la razón de la creación del ser humano, según los textos sagrados mazdeístas, es que funcionen como aliados de Mazda contra Ahrimán, con buenas palabras, buenos pensamientos y buenas acciones, cada día (véase Dadaguí 2012).

24 Si bien es común el uso de la metáfora de árbol para hablar de los hijos de los reyes y héroes, en el caso de Siyawush es un recurso constante. La razón de que Ferdousí, siempre que habla del príncipe, use alguna metáfora vegetal es muy significativo, pues conserva las características míticas de Siyawush como deidad de vegetación (Hosurí 2004: 44-46), una de sus dimensiones más importantes recuperada en el Shahnamé.

25 Cruzarse de brazos en la presencia de un soberano es señal de respeto. 
secretos a la tierra por un largo tiempo. ${ }^{26}$ Luego se acercó al rey; él lo abrazó, le preguntó por Rostam, lo acarició y lo sentó en el trono de turquesa. Estaba tan maravillado de verlo que no paraba de elogiarlo como a los grandes y bendecir su alta estatura y su far. ${ }^{27}$ Vio que bajo la sombra de su protección importantes sucesos ocurrirían: a su tan corta edad era muy sabio, como si de su alma emanara sabiduría. Cantó alabanzas al Creador del universo, frotando el rosto contra la tierra. Hablaba con el Creador del cielo, con el Dueño de la inteligencia y el amor: "Todo lo bueno de este mundo viene de $\mathrm{Ti}$, ante todo Te doy las gracias por este hijo”. Los nobles de Irán, alegres, fueron ante el rey con obsequios. Quedaron deslumbrados por el far de Siyawush y alabaron al Tenedor del mundo. Ordenó a los valientes guerreros que se ciñeran el cinturón de servirles a los nobles iranios. En su palacio, en su jardín y su recinto, un mundo volvió su rostro hacia la alegría. En cada lugar, hicieron una fiesta, mandaron llamar a los músicos, trajeron instrumentos y vino. Ordenó celebrar tal fiesta que ningún soberano del mundo antes que él lo había hecho así. Durante una semana, así estuvieron contentos. En el octavo día, abrió los tesoros y de cada cosa le dio lo mejor a Siyawajsh: de sellos, espadas, tronos y sombreros de reyes, de caballos tayikos con montura de piel de leopardo, de vestimenta de guerra ${ }^{28}$ y armaduras, de monedas, de sedas y joyas. De todo, menos cascos, porque era todavía un niño, y una corona así no le era apropiada. Se los brindó y le dio esperanzas y buenos augurios.

Por siete años lo puso a prueba, y vio que en todo mostraba ser un biennacido. En el octavo año ordenó que le dieran una corona y un cinturón de oro y la tierra de Kavarstán. Según las costumbres de los soberanos y la far de reyes, escribieron un decreto sobre seda por el cual el rey le daba la tierra de Kavarstán, pues él merecía la riqueza y la grandeza. Kavarstán era anteriormente el nombre de la tierra que hoy llamamos Mavara ul-nahr. ${ }^{29}$

26 Siyawush se prosterna y besa el suelo por un largo rato.

27 En el mazdeísmo, la far es una luz divina que Ahura Mazda otorga a quienes son merecedores de ser reyes. Es una luz que se nutre de la sabiduría, la bondad y la justicia (véase Avestá 2013).

28 Jaftán. Una gruesa vestimenta hecha de lana o algodón, especial para guerreros.

29 Mavara ul-nahr, Fararud, en persa, significa 'más allá del río', y se refiere a Transoxiana. 


\section{Palabra acerca del enamoramiento de Sudavé de Siyawajsh}

Cuando Sudavézo vio el rostro de Siyawush, se aturdió y su corazón se incendió. Adelgazó tanto que parecía un hilo, un trozo de hielo puesto ante el fuego. Le envió un mensajero para que le dijera: "No sería extraño si de repente aparecieras en el serrallo del rey”. Él le mandó responder: "No soy hombre de serrallos. No me busques, no soy engañoso". Al otro día, cuando cayó la noche, Sudavé fue ante el rey de Irán con suaves andares y, ligero, le dijo: “¡Oh, rey, dueño del ejército! La luna y el sol no han visto a nadie como tú, y en la tierra no ha visto nadie a alguien como tu hijo. ¡Alégrese el mundo por esta unión! Envíalo a tu serrallo, a donde están sus hermanas. Todas ellas, de caras veladas, tienen el corazón lleno de sangre y el rostro lleno de lágrimas por su amor. Lo adoraremos y le ofreceremos regalos, haremos que el árbol de la admiración se llene de frutos". El rey le respondió: “Es merecida esta palabra. Tú lo quieres con el amor de cien madres".

El dueño del ejército llamó a Siyawajsh y le dijo: "Uno no puede ignorar el amor de quienes son de su sangre y sus raíces. Tras la cortina de mi serrallo, tienes hermanas, y a Sudavé como a una amorosa madre. El puro Creador del universo te creó de tal modo que quien te vea se queda prendado de ti, especialmente los que tienen lazos de sangre contigo. ¿Cómo se sentirán si te ven solo de lejos? Ve a ver a las veladas tras la cortina y quédate un rato para que te halaguen". Cuando Siyawush escuchó las palabras del rey, fijó su mirada en él. Reflexionó con el corazón durante un tiempo e intentó lavarlo de cualquier polvo. Pensó que su padre quería ponerlo a prueba para conocer sus intenciones: "Es sabio, elocuente, inteligente, ve con los ojos del corazón y sospechaba de mí. Si entro en su serrallo, hablarán mal de mí a causa de Sudavé". Siyawajsh respondió: "El rey me ha otorgado el decreto, el trono y el sombrero para gobernar aquel lugar donde el alto sol al salir enaltece la tierra. ${ }^{31}$ No hay rey que tenga tu talante y tu sabiduría ni que esté como tú sobre el camino recto. Hazme sabio con los eruditos, los nobles y los experi-

30 El nombre de la madrastra de Siyawush se ha registrado como Sudabé y Sudavé en distintos manuscritos del Shahnamé. Jaleqi Motlaq prefiere Sudavé.

${ }^{31}$ Motlaq afirma que esta descripción hace referencia a una zona de Jurasán (Shahnamé, p. 575). Por otro lado, uno de los posibles significados de la palabra Jurazm (Corasmia) es 'tierra donde nace el sol' (véase S. P. Tolstov 1948: 78). Teniendo en cuenta la relación del mito de Siyawush con Transoxiana, es posible que dicha descripción haga referencia a Corasmia. De todos modos, el Jurasán iraní formaba parte de la antigua Corasmia antes de que fuera absorbida por el imperio aqueménide en el siglo VII a.C. 
mentados, o batiendo a los de mal pensamiento, armado de lanza, maza, arco y flecha, o en el trono de reyes, en los ritos de recibir a la gente y las costumbres de celebración, de música y de beber vino. ¿Qué puedo aprender en el serrallo del rey? ¿Desde cuándo dirigen a la sabiduría las mujeres?32 Pero, claro, si el rey me lo ordena, lo correcto será obedecerlo”. El rey le dijo: “Alégrate, hijo mío! ¡Que seas siempre origen de sabiduría! Pocas veces son escuchadas palabras tan virtuosas: quien las escucha crece en conocimiento. No dejes que malos pensamientos entren en tu corazón, disponte a la felicidad y sepárate de la tristeza". Siyawush respondió: "Vendré al amanecer y haré lo que ha dicho".

Había un hombre llamado Herzbad, de corazón pulido y lejos del mal. Él tenía la llave del serrallo y jamás lo desatendía. El dueño del ejército le dijo así al veterano: "Cuando el sol desenvaine su espada, ${ }^{33}$ ve ante Siyawush con la mente abierta y haz lo que te ordene. Dile a Sudavé que le obsequie joyas, almizcle y fragancias, y que sus hermanas y las siervas le arrojen peridotos y azafrán”.

Cuando el sol asomó la cabeza por la montaña, Siyawush fue ante el rey. Lo alabó y se prosternó ante él y el dueño del ejército le habló en oculto. Cuando habían terminado, llamó a Herzbad y le dijo lo que era necesario. Luego le habló a Siyawajsh: "Ve con él y engalana los corazones de quienes te volverán a ver". Se fueron juntos con el espíritu alegre y el corazón sin tristezas.

Cuando Herzbad apartó la cortina de la puerta, Siyawush temblaba por temor a la maldad. Repletas de alegría y celebrando, todas las mujeres vinieron a recibirlo. De un extremo a otro había copas llenas de almizcle, azafrán y monedas de oro. Arrojaron monedas bajo sus pies, mezclándolas con perido-

32 Esta pregunta, junto con un par más de versos que aparecen en el fragmento aquí traducido, son los únicos dos versos — de los 50 ooo que conforman el Shahnamé- que hablan con desprecio sobre las mujeres. Un vistazo a las demás reinas y heroínas del libro muestra claramente que la postura de Ferdousí ante la mujer no es la que aquí aparece, sino todo lo contrario, pues las páginas de su Shahnamé están repletas de alabanzas a la belleza, la sabiduría, la astucia y la valentía de las mujeres. El carácter excepcional de este posicionamiento se debe a la presencia de una mujer igualmente inusual, Sudavé, que, a diferencia de todas las demás mujeres del Shahnamé, tiene dos facetas totalmente contradictorias. Es, por un lado, una cariñosa, fiel y valiente esposa para Kawús, y por otro, una mujer malvada y engañosa en su papel de madrastra. Por lo tanto, este alegato de Ferdousí mediante la voz de Siyawush no debe interpretarse como una declaración misógina sino ser comprendida en el contexto total de su obra y en el nivel de otras afirmaciones parecidas del poeta acerca de los héroes o reyes que muestran poca sabiduría y escasas virtudes.

33 Esta metáfora de la salida del sol, que corresponde al día en que Siyawush visite el serrallo por primera vez, es muy bélica y anticipa que en esta visita habrá conflicto. 
tos y ágatas. El suelo estaba cubierto de sedas de China y repleto de perlas de Jushab. ${ }^{34}$ Había vino, música y cantores, todos llevaban gravosos tocados en la cabeza. El serrallo era un ornamentado paraíso, repleto de bellos rostros y riquezas. Al entrar al iwán, 35 Siyawush vio un brillante trono dorado, adornado con turquesas y majestuosamente engalanado con seda. Sudavé, de rostro de luna, estaba en él como un paraíso de colores y fragancias: sentada como la brillante estrella de Yemen, con su ondulada cabellera almizclada que le llegaba a los pies y una alta corona en la cabeza. Una sierva, con la cabeza postrada, estaba de pie a su lado portando un par de zapatos dorados en la mano.

Al pasar Siyawush tras el serrallo, ligera bajó Sudavé del trono. Deslizándose con gracia se acercó y se prosternó ante él. Luego lo abrazó largo rato, le besó largamente los ojos y el rostro y no dejaba de mirarlo mientras decía: “ $\mathrm{C}$ Cien veces gracias al Creador! Lo alabo día y noche ${ }^{36}$ porque nadie tiene un hijo como tú, ni el rey mismo tiene otros parientes semejantes a ti". Siyawush supo cómo era aquel amor: un cariño lejos del camino del Creador. Fue rápidamente hacia sus hermanas, pues ahí no era donde deseaba estar. Las hermanas lo halagaron y lo sentaron en el trono de oro. Tras pasar un largo tiempo con sus hermanas, deslizándose lentamente fue hacia el trono real. El serrallo se llenó de palabras: “QQué cultas cabeza y corona! ¡Es como si no fuera un ser humano! ¡De su alma emana sabiduría!” Siyawajsh fue ante su padre y le dijo: "En tu oculto serrallo vi que posees todo lo bello que hay en el mundo, no tienes razones para quejarte ante el Creador. Tus tesoros, tu armamento y tu palacio superan aquellos de los reyes Yam, Fereydún y Hushang”.37 El rey se alegró por sus palabras. Ordenó que adornaran el iwán como verde primavera y trajeran vino, barbat y ney,,$^{38}$ y así liberaran de todo su corazón.

Cuando el día oscureció y la noche llegó rotando, el renombrado rey entró en su serrallo. Buscó a Sudavé y le dijo: "No debes ocultarme este secreto: cuéntame de los modales y los pensamientos de Siyawush, de su mirar, de su hablar y de su figura, ¿te agradó? ¿es sabio? Si es así, ¡que nadie lo sepa!"

34 Una ciudad de la provincia de Punyab, en Pakistán.

35 El iwán es un pabellón cerrado con una cúpula o libre, rodeado con paredes por tres lados. Es uno de los componentes característicos de los edificios persas.

36 Sudavé dice que alaba a Dios, durante tres fracciones del día y tres fracciones de la noche (los iranios antiguos dividían el día y la noche en cuatro fracciones cada uno). En razón de la fluidez de la traducción, he omitido esta indicación.

37 Algunos de los primeros reyes míticos persas.

$3^{8}$ Barbat es el nombre más antiguo del instrumento que hoy en día se conoce como laúd. Ney es una especie de flauta hecha de una simple caña. 
Sudavé respondió: "El sol y la luna no han visto a nadie como el rey en todo el espacio. ¿Quién hay en el mundo como tu hijo? ¿Por qué hablar de él a escondidas?" El rey le dijo: "Llegará a ser hombre y no deben verlo malos ojos". Sudavé dijo: "Si el rey acepta mi palabra y concuerda con mi opinión de darle como esposa a alguien de su propia sangre y no de otros valientes soberanos, para que su hijo sea igual a él entre todos los valerosos, le diré que 'Yo tengo hijas parecidas a ti, hijas de tu semilla, puramente unidas a ti'; y si prefiere a alguien de la semilla de Kay Arash y Kay Pashín,39 ellas serán felices de ser las elegidas". Él respondió: "Esto es lo que también deseo, pues al final la grandeza estará a mi nombre”.

Al caer la noche, Siyawush fue ante el rey, ensalzando su corona y su posición. El padre habló al hijo en secreto, ocultando la palabra a los extraños. Le dijo: "Al Creador del universo solo le pido un deseo oculto: que, de ti, tu nombre quede de recuerdo y de tu linaje venga un rey al mundo, para que del mismo modo que yo me siento renovado al verte, se te alegre el corazón a ti al verlo a él. La estrella de los sabios, según la palabra de los sacerdotes astrólogos, ha dicho que de tu espalda ${ }^{40}$ habrá un rey a quien todo el mundo siempre recordará. ${ }^{41}$ Ahora mira tras la cortina del serrallo de Kay Pashín y elige a una de las ilustres, y también hay nobles doncellas del linaje de Kay Arash, tú busca y elige a quien quieras". El hijo respondió: "Soy siervo del rey y me someto a sus órdenes y decisiones. Quien él elija para mí, está bien, pues el tenedor del mundo es el rey de sus siervos. Sudavé no debe escuchar esto porque lo contradirá y no lo aceptará. Estas palabras no le conciernen a Sudavé y yo no tengo nada que hacer en tu serrallo". El rey, que no advertía el agua oculta bajo la paja, ${ }^{42}$ se rió de las palabras de Siyawush y le dijo: "Tú debes elegir a tu esposa. No te preocupes por ella y por lo que la gente pueda decir. Ella habla por cariño y quiere cuidar de ti”. Siyawush se alegró de oír estas palabras y su mente se liberó de la preocupación. Alabó al rey y se prosternó ante su trono. Pero para sus adentros estaba pensativo e inquieto a causa de la engañosa Sudavé. Sabía que esto también era idea suya y deseaba desgarrarse la propia piel.

39 Grandes reyes-héroes míticos iranios.

40 De tu linaje.

${ }^{41}$ Se refiere a Kay Josrow, uno de los reyes más importantes del Shahnamé que representa a la figura mesiánica de Sushyanet en la religión mazdea.

42 Es decir, del engaño oculto tras este asunto. 
La noche pasó también por esta historia y el cielo dejó atrás la oscura esfera. Sudavé, alegre, se sentó en el trono. Colocó en su cabeza un tocado de oro y rubíes y luego, la de cara de luna, le dijo a Herzbad: "Ve y dile a Siyawush: 'debes tomarte la molestia de venir y mostrarme el ciprés de tu estatura'”. Siyawush vino ante ella, deslizándose lentamente. Vio aquel trono y aquel tocado. Junto a ella estaban de pie jóvenes ídolos y parecía que el palacio y el serrallo eran el paraíso mismo. Sudavé, con el rostro y la cabellera adornados con joyas, bajó del trono y se acercó a él. Siyawajsh se sentó en el trono dorado y Sudavé se detuvo a su lado con los brazos cruzados. Presentó al joven rey a los ídolos que parecían gemas jamás talladas, y le dijo: "Mira este trono y este espacio, a las muchas siervas con tocados de oro, y a las jóvenes ídolos erguidas que no han madurado todavía y a quienes el Creador ha hecho de pudor y gracia. Dime quién te gusta y mira su cuerpo y rostro". Siyawajsh miró un poco. Ninguna de ellas apartaba de él los ojos; decían entre sí: "Ni la luna resistiría mirar a este rey". Se fueron hacia sus tronos murmurando y maldiciendo su propia fortuna. ${ }^{43}$

Cuando ellas se fueron, Sudavé inquirió: "Dime las palabras ocultas en tu interior. ¿No me dices cuál es tu linaje? Pues en tu rostro está la far del rostro de las parí. Todo aquel que te divise de lejos, pierde la consciencia y te elige a ti. Mira estas bellas caras con el ojo de la sabiduría y ve cuál de ellas te conviene". Siyawush se quedó callado y no respondió. Su puro corazón empezó a recordar: "Que mi puro corazón tenga que sollozar es preferible a elegir esposa entre los enemigos. He oído del más renombrado de los héroes las historias de Hamawarán, de lo que hicieron con el rey de Irán y de cómo desgastaron a los valientes iraníes. ${ }^{44}$ Siendo la tramposa Sudavé su hija, tampoco querrá que mi linaje siga teniendo médula y cáscara”.45 Como Siyawush no abrió la boca para responder, la de cara de parí se quitó el velo del rostro ${ }^{46}$ y le dijo: "El sol y la luna han aparecido juntos en el palacio y no es sorprendente que,

43 Porque Siyawush no elige a ninguna.

44 Sudavé es la hija del rey de Hamawarán. Cuando el rey Kawús, padre de Siyawush, se enamora de ella y la pide como esposa, el rey, que está en desacuerdo con el matrimonio, invita a Kawús y a sus guerreros a un festín que es en realidad una trampa. Ahí los apresa a todos ellos; Rostam y otros héroes iranios consiguen liberarlos tras muchos esfuerzos bélicos (véase Ferdousí 2014, vol. 2: 67-101).

45 Es decir, que siga existiendo.

46 Las mujeres nobles, como parte de su vestimenta, cubrían sus rostros con un fino velo transparente. De todos modos, en el Shahnamé, llevar este velo es símbolo de prudencia (Ferdousí 2014, vol. 9: 581). 
teniendo el sol a tu lado, desprecies la luna. No me sorprende que, al verme a mí, sentada en el trono de marfil y llevando en la cabeza una corona de rubíes y turquesas, no mires a las lunas y de ellas nadie te parezca buena. Si ahora te comprometes conmigo, no vuelves de tu promesa y dejas de preocuparte, haré que una joven doncella esté a tus pies como tu sierva. Hazme un juramento y no rechaces mi palabra. Cuando el rey se marche de este mundo, tú me quedarás de él como recuerdo, no permitirás que me llegue daño alguno y me valorarás como él lo hace. Ahora estoy aquí ante ti, dispuesta a darte mi cuerpo y mi luminosa alma. Te daré todo lo que me pidas, no trataré de salvarme de tu red". Luego, tomó su cabeza en las manos y sin miedo ni vergüenza le dio un amplio beso.

Por vergüenza, el rostro de Siyawush se volvió una roja flor y adornó sus pestañas con cálidas lágrimas de sangre. Le dijo a su corazón: “iQue el Guardián del universo me proteja de la obra del Div!47 No traicionaré a mi padre ni me acercaré a Ahrimán. Si le digo frías palabras a esta desvergonzada, su corazón se calentará de ira y hervirá: recurrirá a una oculta hechicería y al rey del mundo a ella someterá. Es mejor que le hable con voz suave y la mantenga tranquila”. Entonces Siyawajsh le dijo a Sudavé: "En este mundo, tú no tienes semejantes. Te pareces a la media luna y solo el rey te merece. Me bastaría con tu hija y no deseo otra compañera que ella. Ten esto en cuenta y díselo al rey de Irán y mira a ver qué contesta. Quiero comprometerme con ella, pero te prometo que esperaré hasta que crezca y tenga mi edad y hasta entonces no me fijaré en nadie más. Y respecto a tu pregunta acerca de mi rostro, que unió tu alma con mi cariño, te digo que el Creador me creó de su propia far, me formó y protegió bajo Sus alas. ${ }^{4}$ No reveles este secreto y no se lo cuentes a nadie, solo deseo que esta palabra se mantenga oculta. Tú eres la cabeza de las mujeres y soberana, creo que eres como una madre para mí".

Al llegar Kay Kawús al serrallo, Sudavé lo vio y fue ante él: mencionó lo que Siyawush había hecho y le dio al rey buenas noticias: "Vino y miró en el iwán a todos los ídolos de ojos negros que había reunido. Por la presencia de tantos bellos rostros en el iwán, parecía que de la luna surgía el sol. Le agradó solo mi hija y ninguna otra bella le gustó". El rey se alegró tanto de aquellas

47 En el mazdeísmo, div es la palabra que denomina a la fuerza de la oscuridad, Ahrimán, y también a su séquito de demonios.

48 Motlaq señala que esta respuesta de Siyawush refleja la antigua creencia, muy popular en Asia central, de que Siyawush, igual que Yamshid y Kayumart, es el primer hombre sobre la Tierra (Ferdousí 2014, vol. 9: 583). 
palabras que parecía estar junto a la luna. Abrió la puerta del tesoro y dispuso muchas joyas, telas de seda, cinturones de oro, tocados, coronas, anillos, tronos y gargantillas de guerreros. Arregló un tesoro de todas las cosas: era un mundo de riqueza.

Sudavé quedó atónita, tramando en su interior malos pensamientos: "Si él no me obedece, permitiré que mi alma abandone mi cuerpo. Buscaré todas las buenas y malas soluciones que existen en el mundo, descubiertas o escondidas, y si se resiste a mí, lo acusaré ante todos". Se sentó en el trono, con aretes y un colorido tocado y mandó llamar al valiente Siyawajsh. Le habló de todo, diciéndole: "El rey ha dispuesto un tesoro sin igual: innumerable en todas las cosas, tanto que para cargarlo se necesitarían 200 elefantes. Quiere darte a mi hija como esposa; pero mira mi rostro, mi cabellera y mi tocado, ¿qué excusa tienes para darle la espalda a mi amor, a mi semblante y estatura? Desde que te he visto, me siento encadenada, estoy afligida, agitada y alborotada. Siento tanto dolor que el día me parece oscuro, como si el sol se hubiera vuelto lapislázuli. Hace ya siete años que el amor [que siento] me hace derramar lágrimas de sangre. Hazme feliz, a escondidas, y otórgame juventud. Te daré un tesoro mayor a lo que el rey ha dispuesto. Pero si desobedeces mis órdenes y tu corazón no se inclina al compromiso [que te propongo], destruiré tu reinado y haré que tu rostro parezca oscuro a los ojos del rey". Siyawush le respondió: "iQue no llegue nunca el día que entregue mi cabeza al viento a causa del corazón, el día que traicione así a mi padre y me aleje de la sabiduría y la hombría! Tú eres la dama del rey y el sol del palacio; es merecido que no cometas pecado tal". [Sudavé] se levantó del trono, hostil y airada, lo agarró y le dijo: "He revelado ante ti el secreto de mi corazón, ocultándolo a quienes te desean mal. Quieres delatarme, sin razón, y humillarme ante los sabios”. Con sus propias manos se desgarró la ropa y rasguñó sus mejillas con las uñas. Del serrallo se levantó bullicio: sus gritos llegaron del iwán a la calle. El palacio y el iwán desprendían hervor, como si fuera la noche de la Resurrección.

La noticia llegó a los oídos del dueño del ejército. Preocupado, bajó del trono de reyes y fue rápidamente del trono de oro hacia el serrallo. Cuando llegó y vio el rostro arañado de Sudavé y halló el palacio lleno de habla, preguntó a todos y su corazón se encogió: no sabía de lo que tramaba aquella de duro corazón. Sudavé sollozó ante él, derramó lágrimas y se arrancó los cabellos, y dijo: "Siyawush vino a mi trono, riñó conmigo y me sujetó con firmeza, diciendo: 'Mi corazón y alma están repletos de amor por ti, ¿por qué huyes de mí, tú, de bello rostro? No quiero a nadie excepto a ti, y tú debes aceptar mi 
palabra'. Arrancó mi tocado de mi almizclada cabellera y desgarró así mi vestimenta”. Al oír aquellas palabras, el rey se angustió y se dispuso a descubrir la palabra [de la verdad]. Dijo en su corazón: "Si ella dice la verdad y no está buscando hacer maldad, habrá que cortarle a Siyawajsh la cabeza; esta será la solución”. ¿Qué dirían los sabios ahora? Que lo vergonzoso de esta historia tiñe de sangre el sudor.

[El rey] despidió a los que estaban en el serrallo, a los sabios y a los siervos. Se quedó solo en el palacio y llamó ante sí a Siyawajsh y a Sudavé. Con inteligencia y sabiduría, le dijo a Siyawajsh: "No debes ocultarme el secreto. Esto no es culpa tuya; de mí vino la equivocación; estoy afligido por haber pronunciado palabras dañinas: ¿por qué te envié al serrallo? Ahora, mía es la tristeza, y tuya la traición. Busca la verdad y dime: ¿cómo discurrió la palabra? ¡Da la cara!" Siyawush le contó aquello que había sucedido y por lo cual Sudavé estaba enfurecida. Sudavé dijo: "Esto no es cierto. De entre todos los ídolos, él solo deseó mi cuerpo. Le hablé de todo lo que el rey del mundo quería darle abiertamente y a escondidas: de mi hija, de la corona y las riquezas, de las monedas y del tesoro dispuesto. Le dije que yo estaba totalmente de acuerdo con darle todo lo bueno a mi hija. Me dijo que no le importaban las riquezas y que no deseaba ver a mi hija: 'Solo te deseo a ti', dijo, '¡sin ti no me sirven las riquezas ni [me importan] las personas!' Quiso atraparme y hacerme aquello que se hace, me agarró con fuerza con sus manos. Como no le obedecí, me arrancó los cabellos y rasguñó mi rostro. ¡Oh, rey del mundo! Tengo en mi vientre a un hijo de tu semilla y estuvo a punto de morir de tanto que sufrí; el mundo se me había hecho oscuro y estrecho".

El rey se dijo a sí mismo: "Sus palabras no me sirven de nada. No hay que apresurarse, pues la tristeza adormece la sabiduría. Primero, hay que mirar bien; el corazón dará fe de la verdad. Veré quién de los dos es culpable y merece castigo". Como solución para aquella nueva indagación, Kawús olió primero las manos de Siyawush, sus brazos, todo su cuerpo de ciprés. [Luego] encontró en Sudavé olor a vino, almizcle puro y agua de rosas. No halló en Siyawajsh estos olores: no había en él señas de haberla tocado. Se entristeció y despreció a Sudavé, afligió el corazón a causa de ella. Le dijo a su corazón: "Ahora hay que cortarla a ella en trozos con una afilada espada". Entonces temió, [primero], que la voz del dolor alzara revueltas en Hamavarán. Segundo, recordó que cuando estaba apresado y no se hallaba con él ninguno de sus allegados, Sudavé había sufrido día y noche sin abrir los labios [a una queja]. Tercero, pensó que su corazón estaba repleto de amor por ella y que debía ale- 
jar de ella cualquier mal. Cuarto, que tenía hijos pequeños con ella y que no se debe menospreciar la tristeza de los pequeños. Siyawajsh era inocente y el rey sabía de su sabiduría. Le dijo: “¡No te preocupes! ¡Busca la inteligencia, la clarividencia y el conocimiento! ¡Olvida lo sucedido y no lo cuentes a nadie! No vaya a ser que esta palabra se tiña de más colores y aromas".

Cuando Sudavé supo que había sido degradada y que no había podido convencer el corazón del rey, buscó una solución para aquella maldad, plantando un nuevo árbol de rencor: había con ella una mujer en el serrallo, sabedora de hechicería, conjuros y magia; estaba embarazada y debido a la carga que llevaba en su vientre no podía caminar bien. [Sudavé] le reveló su secreto y le pidió ayuda, diciendo: "Primero quiero que me hagas una promesa". Cuando obtuvo el compromiso, le dio mucho oro y le dijo: "No develes esta palabra a nadie. Confecciona una pócima para que bajes tu carga y te vacíes. Y no me delates. Quizá gracias a tus hijos, mi engaño y mentira se aviven. Le diré a Kawús que son mis hijos, muertos por el ataque del malvado Ahrimán. Quizá así consiga culpar a Siyawush. Ahora vete y busca la solución. Si el rey no me escucha, mi honra se oscurecerá y quedaré lejos del trono". La mujer le contestó: "Soy tu sierva; obedeceré todas tus órdenes".

$\mathrm{Al}$ oscurecerse la noche, la mujer tomó la pócima y abortó a los hijos de Ahrimán: dos hijos que parecían hijos de los div, pues ¿cómo podrían ser si su linaje era de hechiceros?49 [Sudavé] trajo una jofaina de oro, llamó a su cuidadora y le contó sus intenciones. Puso en ella a los hijos de Ahrimán, lanzó un alarido y arrojó su cuerpo al lecho. Escondió a la mujer y se acostó: sus gritos llegaron hasta el palacio. Todas las siervas que había en el iwán fueron rápidas ante Sudavé. Vieron a dos niños muertos en una jofaina, y sus alaridos llegaron desde el iwán hasta Saturno. Cuando Kawús oyó los gritos que venían del iwán, tembló en sueños y abrió los oídos. El rey preguntó y le contaron lo que le había sucedido a la de bello rostro. Se entristeció, pero aquella noche no dijo nada. Al alba, se levantó y fue abatido a donde estaba Sudavé. La halló dormida y encontró el serrallo alborotado; vio a aquellos dos niños en la jofaina de oro: muertos ${ }^{50}$ y tirados ahí indignamente. Sudavé llovió agua de los

49 En los textos sagrados del mazdeísmo, la hechicería y la magia están generalmente prohibidas y se consideran obra de los demonios. Es por ello que los hijos de la mujer hechicera son llamados hijos de Ahrimán.

50 Ferdousí utiliza el adjetivo jasteyegar, que literalmente significa 'con el hígado mortificado'. El hígado es un órgano muy importante en la relación que establecen los persas entre el cuerpo y la vida, especialmente a partir del libro El canon de medicina de Avicena, escrito en el siglo XI. Es receptor de sentimientos como ira, angustia, eno- 
ojos y le dijo: “Mira claro el sol!51 Te dije las maldades que él había cometido, pero confiaste en las palabras de él".

El corazón del rey Kawús se tornó desconfiado, se fue y estuvo lleno de preocupación largo rato. Se decía: “¿Cómo encontrarle a esto un remedio? No es merecido que le sea fácil al corazón. ${ }^{22}$ Entonces, el rey Kawús buscó a todos aquellos que leen las estrellas. Los mandó llamar de todas partes y los sentó en el trono de oro. Les habló infinitamente acerca de Sudavé y la batalla de Hamawarán, para que conocieran su situación y deslizaran su compás con sabiduría. ${ }^{53}$ También les habló dilatadamente de aquellos niños y sacó lo oculto de su interior. Todos tomaron sus planisferios y astrolabios y dedicaron una semana a la tarea. Finalmente dijeron: “¿Cómo puede ser que donde han impregnado de veneno haya vino?54 Estos dos niños son de otro padre, no de la espalda del rey ni de esta madre. Si fueran de esencia de reyes, sería fácil determinarlo con el planisferio. Lo sorprendente es que las señas del hombre humilde no se ven ni en el cielo ni en la tierra. ${ }^{55}$ En secreto, le hablaron al rey de la estrella de la impura mujer malvada. Kawús lo mantuvo oculto y no se lo contó a nadie, lo tuvo encubierto en su interior. Así transcurrió una semana más y la copa del mundo se colmó por la hechicería. ${ }^{6}$ Sudavé se quejó y reclamó justicia al rey del mundo, diciendo: "Estoy de acuerdo con el rey si me debe hacer daño o alejarme del trono y del palacio, pero mi corazón se tuerce tanto por el dolor de mis hijos muertos que deseo arrancarme la cabeza del cuerpo”. El rey le dijo: “¡Tranquila, mujer! „No veas solo el hoy, ve el fin!”57 Luego ordenó a sus guardias diurnos para que se encaminaran y buscaran en toda la ciudad y trajeran ante él a la mujer malhechora [que había abortado]. En-

jo y tristeza y su relevancia vital es tanta que incluso a los hijos se les llama yegargushé (un trozo del propio hígado del padre/la madre). Asimismo, es el depositario de los deseos y las esperanzas y también está relacionado con la valentía: tener hígado para hacer algo significa tener la fuerza interior necesaria para llevarlo a cabo.

${ }^{51}$ Mira esta evidencia tan clara.

52 No es merecido no darle importancia.

53 Hace referencia a los instrumentos que los astrólogos utilizan para interpretar las posiciones de los cuerpos celestes.

54 Es decir, donde se suponía que había malas noticias, hay buenas noticias. El vino se ha utilizado con función de antídoto, haciendo referencia a las propiedades curativas que los iranios atribuían a esta bebida (Ferdousí 2014, vol. 9: 590).

55 Hay dos interpretaciones posibles: que no hay señales del hombre humilde que es el padre de los niños, o que las señas de los hombres humildes en general no se reflejan en el cielo ni en la tierra (Ferdousí 2014, vol. 9: 590).

${ }_{56}$ Es decir, el mundo ya no aguantaba más el engaño de la hechicería.

57 No creas que al final todo será como es ahora. 
contraron señales de ella ahí cerca, arrastraron a la pobre mujer por el camino y la llevaron ante el rey, humillándola. Hasta los mayores se apresuraron a ver. El gran soberano le preguntó con amabilidad [acerca de lo sucedido], le dio esperanzas y le prometió buenos días, pero ella no confesó y no convenció al rey. Entonces, la ató y la pegó y dijo a sus guardias: “Sáquenla de aquí y busquen una solución! Si no confiesa, cortadla a la mitad, como mandan las costumbres y los ritos de reyes". Sacaron a la mujer del palacio y le hablaron de la espada, la horca y el calabozo. La hechicera respondió: "Yo soy inocente, ¿qué puedo decir ante el soberano?" Le contaron al rey lo que la mujer había dicho: solo el Creador del mundo sabe lo oculto. Llamó a Sudavé ante sí y le reveló lo que habían determinado los astrólogos: "Estos dos niños se parecen a la mujer hechicera y son hijos de Ahrimán”. Sudavé de nuevo respondió: "Ellos saben más secretos que esto, ocultan más palabra en su interior, pero no pueden decir nada por Siyawush: por el temor al comandante de cuerpo de elefante, hasta los leones tiemblan, porque tiene la fuerza de 8 o elefantes y si quiere puede cortar la corriente del río Nilo. Los valientes ejércitos de 100 ooo soldados huyen de él en las batallas. ¿Cómo puedo enfrentarlo yo? Solo me queda tener siempre los ojos llenos de sangre. ¿Qué dicen los astrólogos excepto lo que les ordena decir quien los recompensará? Si no te importan tus pequeños hijos, a mí tampoco me une nada más a ellos. Como has tomado este asunto a la ligera, esperaré que se me haga justicia en el otro mundo". Derramó de sus ojos tanta agua que superaba lo que toma el sol del Nilo.

El dueño del ejército se afligió por sus palabras y empezó a llorar junto con ella. Mandó de vuelta [al serrallo] a Sudavé, pero su corazón seguía puesto en el dolor; se decía: "Investigaremos este asunto ocultamente, a ver cuál es el resultado". Llamó a todos los sacerdotes y les habló de Sudavé largo rato. Los sacerdotes le dijeron al rey: "El dolor que siente el dueño del ejército no quedará oculto. Si deseas saber la verdad hay que lanzarle una piedra al vaso..$^{8}$ Aunque son queridos los hijos, el corazón del rey está afligido de preocupación; y, por otro lado, está angustiado por la hija del rey de Hamawarán. Como ambos sostienen su palabra, uno de ellos debe pasar por el fuego. La alta rueda59 ha determinado que los inocentes saldrán indemnes." El tenedor del mundo llamó a Sudavé ante sí y la sentó con Siyawush para que hablaran del mal [sucedido]. Finalmente dijo: "Mi corazón no se sentirá seguro de ninguno, ni mi alma

58 Significa poner a prueba algo o a alguien, llevándolo a sus límites y arriesgándolo.

59 El cielo. 
quedará tranquila, a no ser que el ardiente fuego encuentre al culpable y lo delate". Sudavé contestó: "Yo he dicho la verdad. Malogré dos hijos del rey: nadie sabe de una falta mayor. Siyawajsh es quien debe mostrar que no cometió esta maldad”. El rey de la tierra le preguntó a Siyawajsh: “Qué opinas tú de esto?" Siyawush le respondió: “A causa de estas palabras, [hasta el fuego] del infierno me parece insignificante. Pasaré por la montaña de fuego si es necesario; no me negaré”. El alma de Kay Kawús se llenó de preocupación por su hijo y por su querida Sudavé: "Si uno de los dos resulta malhechor, ¿quién me llamará rey a partir de entonces? ¿Quién puede hacer buenas acciones si su mente está hirviendo a causa de su hijo y su esposa? Es mejor que lave mi corazón de estas malas palabras y busque un remedio que libere el corazón. ¡Qué bien dijo aquel rey elocuente: 'No reines con el corazón doliente'!"

\section{Palabras acerca del paso de Siyawajsh por el fuego}

Ordenó a los camelleros que trajeran del llano 100 caravanas de camellos. Cargaron de leña los camellos y todo el país de Irán fue a mirar. Cien caravanas de bramantes camellos pelirrojos trajeron leña. Apilaron dos altas montañas de la innumerable leña: cualquiera las veía de dos leguas de distancia. [El rey] quería ver la verdad y esta debía ser la solución. Ahora que escuches esta historia, sabrás que es más conveniente no inclinarse hacia las mujeres: pues hay muchas fallas en sus acciones. En el llano apilaron dos montañas de leña, todo un mundo se reunió a mirar. El paso entre las dos pilas era suficientemente ancho para permitir pasar a cuatro jinetes que cabalgaran a la par: así eran la costumbre y el rito de aquella prueba del poderoso rey. Entonces, el rey ordenó a los sacerdotes que tiraran negra nafta a la leña. Vinieron 200 hombres a encender el fuego, soplaron y la noche se volvió día. Con el primer soplo, salió humo negro y después, rápido, se elevó la lengua del fuego. La tierra se tornó más luminosa que el cielo, el fuego estaba vivo y la gente, agitada.

Siyawush vino hacia su padre, llevando en la cabeza una celada de oro. Todo el llano ardió en lágrimas al ver su sonriente rostro. Lúcido, vestido de blanco, los labios desbordados de sonrisa y el corazón lleno de esperanza, montaba un negro corcel cuyos cascos levantaban polvo hasta la luna. Se había esparcido alcanfor por el cuerpo, como se acostumbra al ponerse el sudario. Cuando llegó ante Kawús, bajó del caballo y se prosternó. Vio el rostro del rey Kawús rebosante de vergüenza. Vio que era suave su hablar con su hijo. 
Siyawush le dijo: "No estés triste. Así gira el mundo. Mi cabeza está repleta de vergüenza y tengo valor: si soy inocente, me libraré. Pero si soy culpable, ¡que Dios no me guarde! Con el poder del bondadoso Creador, me salvaré de esta montaña de fuego". Del llano y de la ciudad se levantó bullicio; el mundo entero se entristeció. Cuando Sudavé escuchó los gritos, salió al iwán y vio el fuego; deseó que el mal lo alcanzara, hirviendo de angustia. Todo un mundo, con las lenguas repletas de maldiciones y los corazones de ira, tenía sus ojos fijados en Kawús.

Siyawush cabalgó hacia aquella montaña de fuego, no se asustó, se preparó a enfrentarla. La lengua del fuego se alzaba por doquier y nadie pudo ver el casco y el caballo de Siyawush. En la planicie, estaban todos con los ojos llenos de sangre, esperando que él saliera del fuego. Cuando lo vieron, alzaron la voz diciendo: “El nuevo rey ha salido del fuego!” Aun si [en vez de fuego] hubiera pasado por agua, su vestimenta estaría mojada, pero el caballo y la ropa del jinete lucían impolutos como un jazmín. ${ }^{60}$ Cuando el puro Creador perdona, son iguales el aliento del fuego y el del agua. Cuando de la montaña de fuego pasó a la planicie, el llano y la ciudad levantaron clamor. Los jinetes del ejército se alzaron y todos los presentes le arrojaron monedas. El mundo entero, tanto los nobles como los plebeyos, estaba alegre. Todos repetían la feliz noticia de que "El Justo ha perdonado al inocente".

Sudavé, por rabia, se arrancaba los cabellos, lloraba y se rasguñaba el rostro. Cuando Siyawajsh fue ante su padre, estaba limpio, sin rastro del fuego y ni de humo ni de polvo alguno. El rey Kawús, comandante del ejército, bajó de su caballo y lo mismo hizo su ejército. Abrazó a Siyawajsh con fuerza y le pidió disculpas por su mal comportamiento. Ante el puro dueño del mundo, Siyawajsh frotó su rostro contra el suelo, pues se había salvado del ardor de aquella montaña de fuego, frustrando los deseos de sus enemigos. El rey le dijo: “'Oh joven valiente, de semilla pura y alma luminosa! ¡Bendito aquel que nace de madre virtuosa, pues será el rey del mundo!” Se deslizó con alegría hacia el iwán; se sentó y se colocó el sombrero de reyes en la cabeza. Mandó traer vino y llamó a los músicos, disfrutando con Siyawush de todo. Durante tres días tomaron vino y la puerta del tesoro no estuvo cerrada. Al cuarto día,

6o Ferdousí enfatiza el hecho de que Siyawush sale del fuego totalmente indemne y que su ropa blanca no presenta ninguna señal de humo. Shahroj Meskub argumenta que el fuego no daña a Siyawush, no solo por su inocencia, sino porque él y el fuego comparten la misma esencia, a saber, la luz de Mazda (Meskub 2015: 49-50). 
se sentó en el trono de grandeza, en su mano la maza de cabeza bovina. ${ }^{61}$ Con ira, mandó llamar a Sudavé y le habló de lo que había pasado: "Te has portado con maldad y sin vergüenza y has hecho sufrir a mi corazón en demasía. Al final, sirviéndote así de la brujería, jugaste con la vida de mi hijo y lo arrojaste al fuego. Pedir disculpas ya no sirve de nada: iprepárate para dejar este mundo como un adorno de la horca! Tú no mereces estar en la tierra, ¡tu merecido es solo la horca!" Ella le dijo: "Si mi castigo es que me corten la cabeza por ese mal que me ha alcanzado, que sea lo que tú ordenes. Mi corazón lo acepta porque no quiero que me tengas rencor. Siyawush dice la verdad y lava el corazón del rey con el fuego, [pero] todo esto es hechicería de Zal; si no, el fuego ardiente no sería mi enemigo”.62 [Kawús] le respondió: “¡Todavía intentas engañarme! ¡No se dobla la espalda de tu maldad!” Luego, el rey del mundo les preguntó a los iranios: “¿Cuál debe ser el castigo de ella por el mal que ha cometido a escondidas?" Todos alabaron al rey y contestaron: "Su castigo debe ser perder la vida; así sufrirá por el mal cometido”. Kawús ordenó al verdugo: "Llévatela a la calle y ahórcala. Termina este trabajo".

Cuando agarraron a Sudavé, todo el serrallo lanzó un grito. El corazón del rey Kawús se llenó de dolor; lo ocultó, pero su rostro tornose amarillo. Siyawush habló con el rey y le dijo así: "No entristezcas tu corazón por esto. Perdona a Sudavé por mí. Quizá así vuelva al camino [recto], a los consejos y a las [buenas] costumbres". Pues en su corazón estaba pensando: "Si Sudavé muere a manos del rey, este se arrepentirá al final y me acusará a mí del mal que lo afligirá". El rey, que buscaba una excusa para perdonar la culpa cometida, le dijo a Siyawajsh: "Aunque había decidido derramar su sangre, la perdono". Siyawush besó el trono de su padre, se levantó y se fue. Las mujeres del serrallo volvieron ante Sudavé y se prosternaron ante ella una a una.

Así pasó también un tiempo y el corazón del rey recuperó su calor por ella, hasta que, de nuevo, se llenó tanto de su amor que no quitaba su mirada del rostro de ella. Sudavé, a escondidas, de nuevo hechizó al rey del mundo para que pensara mal de Siyawajsh como es esperado de los que tienen mala esen-

${ }^{61}$ A partir de Fereydún, todos los reyes iranios portan su maza de cabeza bovina, símbolo de justicia y victoria sobre el mal que en su tiempo fue representado por Zahak, con todas sus dimensiones míticas, religiosas y políticas (véase Mohammadi 2018: 93-135).

62 Sudavé acusa a Zal de haber hecho que Siyawush sea inmune al fuego. Zal es el padre de Rostam y su vida está repleta de acontecimientos mágicos (véase Ferdousí 2011). 
cia. Escuchándola, [Kawús] volvió a dudar de él, aunque en ese momento no se lo reveló a nadie.

Cuando así ocurren las cosas, hacen falta la sabiduría, la justicia y la fe. Hay que ser precavidos, como los sabios, para que todo resulte como uno lo desea. Tú no eres suficiente para crear, así que no te enfades si no comprendes la acción del Creador. Así se comporta la rueda giratoria: no quiere mostrarte su rostro amable. Esta historia te enseña algo: que no hay amor que supere los lazos de sangre. Cuando haya aparecido un hijo merecido, hay que alejar el corazón del amor de las mujeres.

\section{Bibliografía}

Avestá (2013). Trad. y ed. Yalil Dustjah, Teherán, Morvarid.

BaHAR, Mehrdad (2014). Payuheshi dar asatir-e irán [Indagaciones en los mitos iranios], Teherán, Agah.

DADAGUí, Farnbagh (2012). Bundahishn, trad., ed., notas e introducción Mehrdad Bahar, Teherán, Tús.

Ferdousí, Abol Qasem (2011). El libro de los reyes. Las historias de Zal, Rostam y Sohrab, trad. Clara Janés y Ahmad Taherí, Madrid, Alianza.

Ferdousí, Abol Qasem (2014). Shahnamé, ed. Yalal Jaleqí Motlaq, 12 vols., Teherán, Markaz-e Dayeratolma'aref-e Bozorg-e Eslamí.

Gimbutas, Marija (2001). The Language of the Goddess, London, Thames \& Hudson. Hosurí, Alí (2004). Siyawushán, 2å. ed., Teherán, Cheshmé.

Meskub, Shahroj (2015). Sug-e Siyawush (dar marg va rastajiz), 8ạ. ed., Teherán, Jarazmí.

Mohammadi Shirmahaleh, Shekoufeh (2018). "El Shahnamé: la historia de Ŷamšīd, Zahāk y Fereydún. Introducción, traducción y notas”, Interpretatio. Revista de Hermenéutica, vol. 3, núm. 1: 93-135.

Tolstov, Sergey Pavlovich (1948). По следам древнехорезмийской цивилизации [Siguiendo las huellas de la Antigua civilización de Corasmia], Moscú, MSU.

\section{Shekoufeh Mohammadi Shirmahaleh}

Doctora en Lingüística Aplicada por la Universidad de Alicante. Su carrera profesional abarca la investigación, la docencia y la traducción. Actualmente es investigadora del Seminario de Hermenéutica del Instituto de Investigaciones Filológicas de la UNAM, y como investigadora se ha dedicado a las aplicaciones de la semiótica a la literatura y las artes, teniendo la cultura y el arte persas como el centro de sus estudios. Sus líneas de investigación incluyen la hermenéutica literaria, la hermenéutica del símbolo y la hermenéutica cultural. Entre 
Interpretatio, 4.2, septiembre 2019-febrero 2020: 49-74

sus últimas publicaciones están: Sintiendo la palabra. Contextos lingüísticos y literarios del icono metafórico (2016), y, como editora, Mito, épica e identidad. El presente como metáfora del ayer (2019). 